\title{
Effect of Graded Coronary Constriction on the Flow Reserve in Regional Myocardium in Dog
}

\author{
Shoichi Haraoka, M.D., Daiji Saito, M.D.,* Shozo Kusachi, M.D.,* \\ Taiji Sogo, M.D.,* Nobuyuki Yamada, M.D.,* \\ Osamu Nishiyama, M.D., ${ }^{*}$ and Koichiro Yasuhara, M.D.,
}

\section{SUMmary}

Effects of coronary constriction on the flow reserve of regional myocardium were studied in the anesthetized open-chest dogs. Regional myocardial bloed flow (RMBF) was continuously measured using heated crossthermocouple method. Left circumflex coronary artery (LCX) was constricted gradually with a screw type constrictor. The coronary constriction decreased subendocardial myocardial blood flow, while subepicardial myocardial blood flow was not affected until reactive hyperemia in LCX nearly disappeared. Recovery and arrival to peak flow rate of RMBF following the release of 15-second's occlusion of LCX were progressively delayed with an increase in the constriction, especially in the subendocardial myocardium. Repayment of flow debt, however, was remained relatively well since the duration of reactive hyperemia in $\mathrm{RMBF}$ was prolonged by an increment of the constriction.

From these findings, it might be concluded that in the heart with coronary stenosis recovery from ischemia was caused by prolonged duration of reactive hyperemia, and is suggested that the time required for recovery from ischemia or ischemic abnormalities after the cessasion of stress might be an important marker for the severity of coronary insufficiency.

\section{Additional Indexing Words :}

Reactive hyperemia Coronary stenosis Local myocardial flow

$1 \begin{aligned} & \text { ARKED myocardial reactive hyperemia occurs following a brief period } \\ & \text { of coronary artery occlusion in either open-chest }{ }^{1)} \text { or conscious dogs, }{ }^{2} \text { ) }\end{aligned}$ and the increase in coronary blood flow is reproducible for a given period of occlusion provided that the preocclusion coronary blood flow remains unchanged. Although the mechanism responsible for myocardial reactive hyperemia remains unknown, estimation of peak reactive hyperemic flow following a coronary artery occlusion for longer than 5-7 sec, probably better

From the Central Laboratory and the First Department of Internal Medicine, Okayama University Medical School, Okayama 700, Japan.

Address for reprints: Shoichi Haraoka, M.D., Central Laboratory, Okayama University Medical School, 2-5-1 Shikata-cho, Okayama 700, Japan.

Received for publication August 21, 1978. 
to say $15-30 \mathrm{sec}$, is a convenient way to estimate the maximum vasodilator capacity of this vascular system, because there is no known stimulus to coronary vasodilation greater than that produced by ischemia. Constriction of a coronary artery decreases reactive hyperemia and by reducing coronary perfusion pressure, causes subendocardial ischemia. ${ }^{37}$ The non-uniform distribution of blood flow within the myocardium is believed to be due to a smaller flow reserve in the subendocardial myocardium resulting from higher wall stress. ${ }^{4 \prime}$

The present investigation was designed to study the effect of coronary artery constriction on transmural flow distribution and on coronary flow reserve as estimated by the hyperemic response to brief coronary occlusions.

\section{Materials and Methods}

Experiments were conducted in 15 mongrel dogs anesthetized with sodium pentobarbital (25-30 $\mathrm{mg} / \mathrm{Kg}$, i.v.) and ventilated with room air through an endotracheal tube. The heart was exposed through a thoracotomy in the left fifth intercostal space. The circumflex coronary artery (LCX) was isolated and an electromagnetic blood flow transducer (Type MF-26, Nihon-Koden, Tokyo) was positioned 1-2 cm below its origin. A screw type constrictor and a loose ligature were placed just distal to the transducer. The ends of the ligature were threaded through a short plastic tube for occluding the vessel. Cannulae were placed in the abdominal aorta via the right femoral artery for monitoring arterial blood pressure, in the left ventricle via the left carotid artery for monitoring left ventricular pressure and in the right femoral vein for administering heparin and additional anesthetic as required.

Two heated cross-thermocouple electrodes, $100 \mu \mathrm{m}$ in diameter, (Type CTE202, Shin-Ei, Tokyo) were used for the assessment of apparent myocardial thermal conductivity increment, which was directly proportional to local tissue blood flow. ${ }^{5)}$ One electrode was implanted in the inner third of left ventricular wall in the central area supplied by LCX and the other in the outer third in the same area. The position of the thermocouples was verified at the end of each experiment. If a probe was improperly positioned, the data of the experiment were not included. Since the heated cross-thermocouple methed does not provide an absolute value for myocardial blood flow (RMBF), estimates of RMBF are expressed in terms of the compensating voltage at the measuring point.

Following control measurements, the LCX was gently occluded with the ligature for $15 \mathrm{sec}$ and the hyperemic response after the release of the occlusion was recorded. The vessel was then constricted with the constrictor to a desired degree and the reactive hyperemia after another 15-second's occlusion was recorded.

The data obtained were classified into 4 groups on the basis of the magnitude of peak reactive hyperemia $(\mathrm{PRH})$ :

Group A: without coronary constriction (PRH exceeded 250\% of resting flow rate).

Group B: PRH was from 150 to $200 \%$ of resting flow rate. 
Group C: PRH was from 120 to $150 \%$ of resting flow rate.

Group D: no significant hyperemia (PRH was below 120\% of resting flow rate).

Calculations of reactive hyperemia flow, repayment of flow debt and flow debt of coronary blood flow were made as described by Coffman and Gregg. ${ }^{6}$ ) In RMBF the flow debt was calculated as follows:

Flow debt of RMBF $(\mu \mathrm{V} \mathrm{sec})=$ resting flow rate $(\mu \mathrm{V}) \times$ duration (sec) from the onset of occlusion to the time when RMBF recovered to the resting flow rate-total flow during the same period.

The unpaired Student's t-test was used for comparisons of the data between the groups, and paired Student's t-test was used for comparisons within the same group.

\section{REsults}

The occlusion of LCX for $15 \mathrm{sec}$ caused insignificant changes in aortic blood pressure and heart rate. Left ventricular end-diastolic pressure (LVEDP) rose slightly in groups $\mathbf{A}$ and $\mathbf{B}$ and significantly in groups $\mathrm{C}(\mathrm{p}<$ $0.01)$ and $D(p<0.001)$. The rise in LVEDP was proportional to the degree of the constriction as shown in Table $I$.

\section{Coronary blood flow (Table I)}

Coronary artery constriction progressively reduced the volume of reactive hyperemia flow. This reduction was resulted from a decrease in PRH and shortening of the duration of reactive hyperemia, which lasted $45 \pm 11.2$ (mean $\pm \mathrm{SD})$ sec in group $\mathrm{A}$ and $32 \pm 10.1 \mathrm{sec}$ in group $\mathrm{C}(\mathrm{p}<0.001)$. No reactive hyperemia was observed in group $D$. The flow debt incurred during occlusion was overpaid in group A, while with coronary constriction the repayment of flow debt markedly decreased due to a reduction of reactive hyperemia flow. The flow debt was underpaid in group C. Therefore, flow debt was just repaid in the heart with the constriction of the vessel producing PRH approximately $150 \%$ of the control. In this situation resting coronary blood flow rate was $80 \%$ of that without coronary constriction (Fig. 1).

\section{Regional myocardial blood flow (Taole $\mathrm{II}$ )}

The data of regional myocardial blood flow (RMBF) are summarized in Table II, and Fig. 2 illustrates experiments in groups A and D.

Resting RMBF in the inner third of left ventricular wall was nearly equal to that in the outer third without coronary constriction, the flow ratio of the inner to outer third ( $\mathrm{I} / \mathrm{O}$ ratio) averaging $0.98 \pm 0.062$. Stepwise coronary constriction caused a reduction in $\mathrm{RMBF}$ of the inner third, whereas $\mathrm{RMBF}$ of the outer third remained unchanged even when reactive hyperemia 
Table I. Coronary Blood Flow and LVEDP with or without Coronary Constriction

\begin{tabular}{|c|c|c|c|c|c|c|c|c|}
\hline & & \multicolumn{5}{|c|}{ Coronary blood Flow (per $100 \mathrm{Gm}$ heart muscle) } & \multicolumn{2}{|c|}{ LVEDP (mmHg) } \\
\hline & & $\begin{array}{c}\text { resting } \\
\text { flow } \\
\text { (ml/min) }\end{array}$ & $\begin{array}{l}\text { How debt } \\
\text { (ml) }\end{array}$ & $\begin{array}{c}\text { PRH } \\
(\mathrm{ml} / \mathrm{min})\end{array}$ & $\begin{array}{l}\text { RH flow } \\
\text { (ml) }\end{array}$ & $\begin{array}{c}\text { repayment } \\
(\%)\end{array}$ & resting & $\begin{array}{l}\text { immed. } \\
\text { after } \\
\text { release }\end{array}$ \\
\hline \multirow[t]{2}{*}{ no constriction } & $\mathrm{m}$ & 76.4 & 19.1 & 348.7 & +68.9 & +356.8 & 5.1 & 5.8 \\
\hline & $\mathrm{SD}$ & 10.91 & 5.10 & 44.01 & 10.41 & 54.40 & 1.2 & 2.0 \\
\hline \multirow[t]{2}{*}{ PRH $150-200 \%$} & $\mathrm{~m}$ & $60.0^{*}$ & $14.9^{*}$ & $102.2 * *$ & $+1.9 * *$ & $+14.3 * *$ & 6.5 & 7.5 \\
\hline & SD & 13.32 & 3.33 & 20.53 & 2.01 & 8.61 & 2.1 & 2.6 \\
\hline \multirow[t]{2}{*}{ PRH $120-150 \%$} & $\mathrm{~m}$ & $56.0^{* *}$ & $13.9^{*}$ & $77.8 * *$ & $-5.8 * *$ & $-40.9 * *$ & 8.0 & $11.8^{8}$ \\
\hline & $\mathrm{SD}$ & 10.85 & 2.71 & 21.69 & 2.88 & 15.27 & 2.4 & 3.0 \\
\hline \multirow[t]{2}{*}{ PRH (-) } & $\mathrm{m}$ & $53.5^{* *}$ & $13.0 *$ & $53.7 * *$ & $-12.9 * *$ & $-98.6^{* *}$ & 9.8 & 15.085 \\
\hline & $\mathrm{SD}$ & 15.53 & 3.93 & 15.47 & 1.53 & 6.21 & 2.6 & 3.7 \\
\hline
\end{tabular}

$\mathrm{PRH}=$ peak reactive hyperemic flow, $\mathrm{RH}=$ reactive hyperemic flow, LVEDP=left ventricular end-diastolic pressure, $\mathrm{m}=$ mean, $\mathrm{SD}=$ standard deviation.

Statistical differences from non-constricted group; ${ }^{*} \mathrm{p}<0.01,{ }^{* *} \mathrm{p}<0.001$.

Statistical difference from the resting values; \& $\mathrm{p}<0.01$, \$\$ $\mathrm{p}<0.001$.

Table II. Regional Myocardial Blood Flow

\begin{tabular}{|c|c|c|c|c|c|}
\hline & & & $\begin{array}{l}\text { resting flow } \\
(\mu V)\end{array}$ & $\begin{array}{l}\text { minimum flow } \\
\text { during } \\
\text { occlusion } \\
(\mu \mathrm{V})\end{array}$ & $\begin{array}{l}\text { flow debt } \\
(\mu \mathrm{V} \text { sec) }\end{array}$ \\
\hline \multirow[t]{4}{*}{ no constriction } & inner & $\mathrm{m}$ & 15.6 & 8.5 & 82.9 \\
\hline & & $\mathrm{SD}$ & 2.69 & 2.05 & 7.86 \\
\hline & outer & $\mathrm{m}$ & 16.1 & 10.3 & 58.2 \\
\hline & & $\mathrm{SD}$ & 2.46 & 2.02 & 6.15 \\
\hline \multirow[t]{4}{*}{ PRH $150-200 \%$} & inner & $\mathrm{m}$ & 14.0 & 8.0 & 84.1 \\
\hline & & $\mathrm{SD}$ & 2.12 & 2.31 & 9.25 \\
\hline & outer & $\mathrm{m}$ & 16.8 & 10.5 & $78.7 * *$ \\
\hline & & $\mathrm{SD}$ & 1.90 & 2.05 & 9.16 \\
\hline \multirow[t]{4}{*}{ PRH $120-150 \%$} & inner & $\mathrm{m}$ & $12.5^{*}$ & 7.0 & $118.2^{* * *}$ \\
\hline & & SD & 1.79 & 1.51 & 17.80 \\
\hline & outer & $\mathrm{m}$ & 16.7 & 11.0 & $89.6^{* *}$ \\
\hline & & $\mathrm{SD}$ & 2.07 & 1.61 & 10.01 \\
\hline \multirow[t]{4}{*}{$\mathrm{RH}(-)$} & inner & $\mathrm{m}$ & $10.2 * *$ & $6.0 *$ & $263.0^{* * *}$ \\
\hline & & $\mathrm{SD}$ & 1.80 & 1.27 & 29.05 \\
\hline & outer & $\mathrm{m}$ & 16.0 & 10.9 & $132.6^{* *}$ \\
\hline & & SD & 2.61 & 1.81 & 10.16 \\
\hline
\end{tabular}

$\mathrm{PRH}=$ peak reactive hyperemic flow ; min.=minimum value during coronary occlusion ; $\mathrm{RH}=$ reactive hyperemia; $\mathrm{RH}$ flow = reactive hyperemia flow; $\mathrm{m}=$ mean; $\mathrm{SD}=$ standard deviation. 

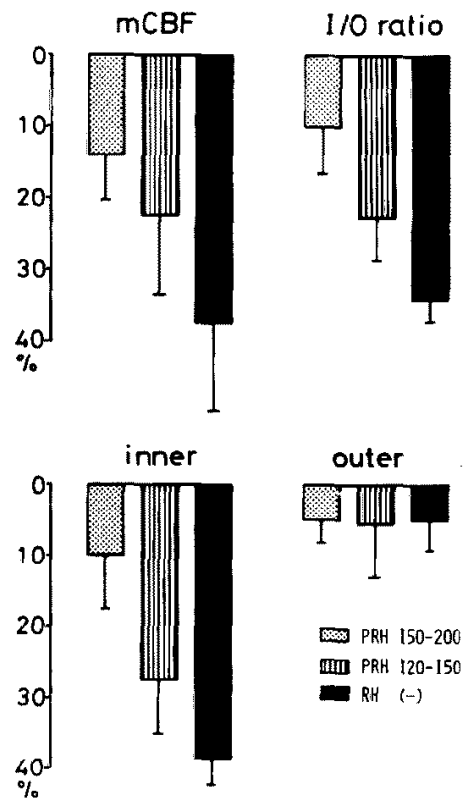

$150-200$;

ㅁII PRH 120-150:

RH (-)

Fig. 1. Effects of coronary constriction on resting coronary and regional myocardial blood flow. $m C B F=$ mean coronary blood flow, inner $=$ inner third of left ventricular wall, outer $=$ outher third of left ventricular wall, $\mathrm{I} / \mathrm{O}$ ratio=blood flow ratio of the inner to outer third.

with or without Coronary Constriction

\begin{tabular}{|c|c|c|c|c|c|}
\hline \multicolumn{6}{|c|}{$\mathbf{R H}$} \\
\hline \multicolumn{2}{|c|}{ peak flow } & \multicolumn{2}{|c|}{ over shoot } & \multirow{2}{*}{$\begin{array}{l}\text { RH flow } \\
(\mu \mathrm{V} \text { sec })\end{array}$} & \multirow{2}{*}{$\begin{array}{l}\text { repayment } \\
(\%)\end{array}$} \\
\hline time (sec) & vol. $(\mu \mathrm{V})$ & onset (sec) & end (sec) & & \\
\hline 20 & 22.0 & 6 & 84 & +187.8 & +255.3 \\
\hline 8.4 & 3.44 & 3.8 & 11.5 & 40.71 & 39.20 \\
\hline 13 & 22.4 & 3 & 81 & +174.2 & +313.9 \\
\hline 3.6 & 3.09 & 1.4 & 11.9 & 38.17 & 60.82 \\
\hline $33 *$ & $16.5 * *$ & $14 *$ & $98 t$ & $+101.6^{* *}$ & $+108.0^{* *}$ \\
\hline 10.8 & 2.09 & 7.1 & 19.5 & 20.74 & 30.24 \\
\hline $21^{* *}$ & 21.8 & $10^{* *}$ & 80 & $+100.8^{* *}$ & $+136.1^{* *}$ \\
\hline 6.5 & 3.01 & 4.2 & 14.0 & 30.26 & 44.10 \\
\hline $63 * *$ & $14.8 * *$ & $28 * *$ & $136^{* *}$ & $+19.8 * *$ & $+17.5 * *$ \\
\hline 18.9 & 2.07 & 11.6 & 26.2 & 26.5 & 25.23 \\
\hline $40^{* *}$ & $19.8 \dagger$ & $17 * *$ & 88 & $+23.9 * *$ & $+29.1 * *$ \\
\hline 10.9 & 2.62 & 11.6 & 17.2 & 20.30 & 29.25 \\
\hline $100 * *$ & $10.2 * *$ & $(100)$ & - & $-262.1 * *$ & $-99.2 * *$ \\
\hline 29.2 & 2.01 & $(2.01)$ & - & 31.42 & 9.06 \\
\hline $7 b^{* * *}$ & $16.9 *$ & $37 *$ & $113 * *$ & $-110.6^{* *}$ & $-94.5 * *$ \\
\hline 10.1 & 2.01 & 15.0 & 22.1 & 33.26 & 3.25 \\
\hline
\end{tabular}

Statistical differences from non-constricted group; $+\mathrm{p}<0.05, * p<0.01,{ }^{*} * \mathrm{p}<0.001$. 


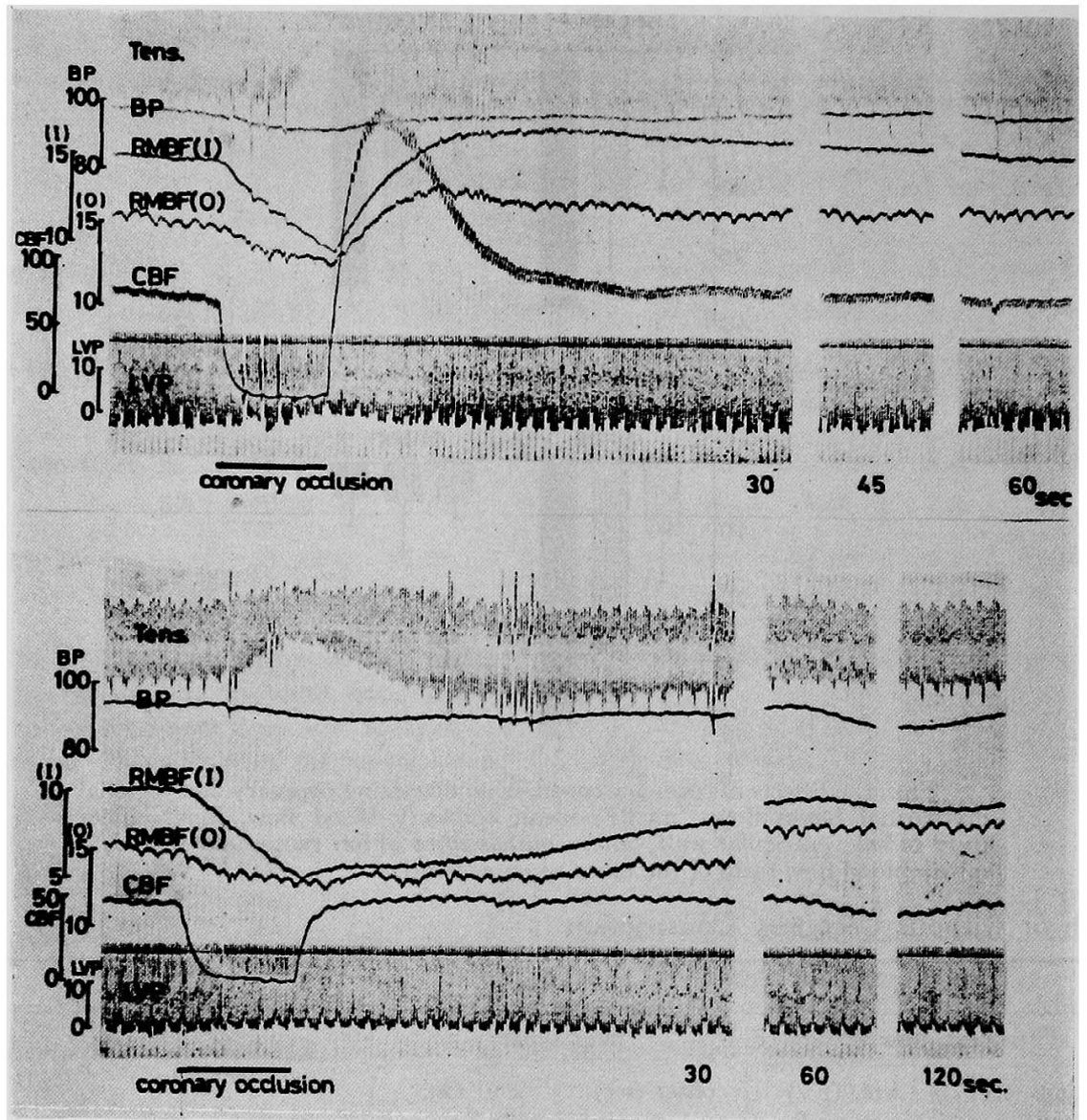

Fig. 2. Actual cases of group A (upper) and group D (lower). Tens.= contraction curve of left ventricular wall, $\mathrm{BP}=$ aortic blood pressure, $\mathrm{RMBF}=$ regional myocardial blood flow, $(I)=$ inner third of left ventricular wall, $\mathrm{CBF}=$ coronary blood flow (left circumflex branch), LVP=left ventricular pressure.

disappeared (Fig. 1).

Following the release of the total occlusion RMBF returned to the resting flow level and thereafter showed overshoot in both layers. The attaining of PRH was delayed in proportion to the degree of coronary constriction, especially in the inner third as shown in Fig. 3. The magnitude of PRH was significantly greater in the outer third, while the percentage increase in PRH was similar in both layers at each level of constriction. The ratio of the peak flow rate in the inner to outer third progressively decreased in association with an increase in constriction (Fig. 4). Flow debt in RMBF was repaid gradually due to a delayed return to the resting level, and the flow debt of the inner third was greater than that of the outer third at any level of the con- 


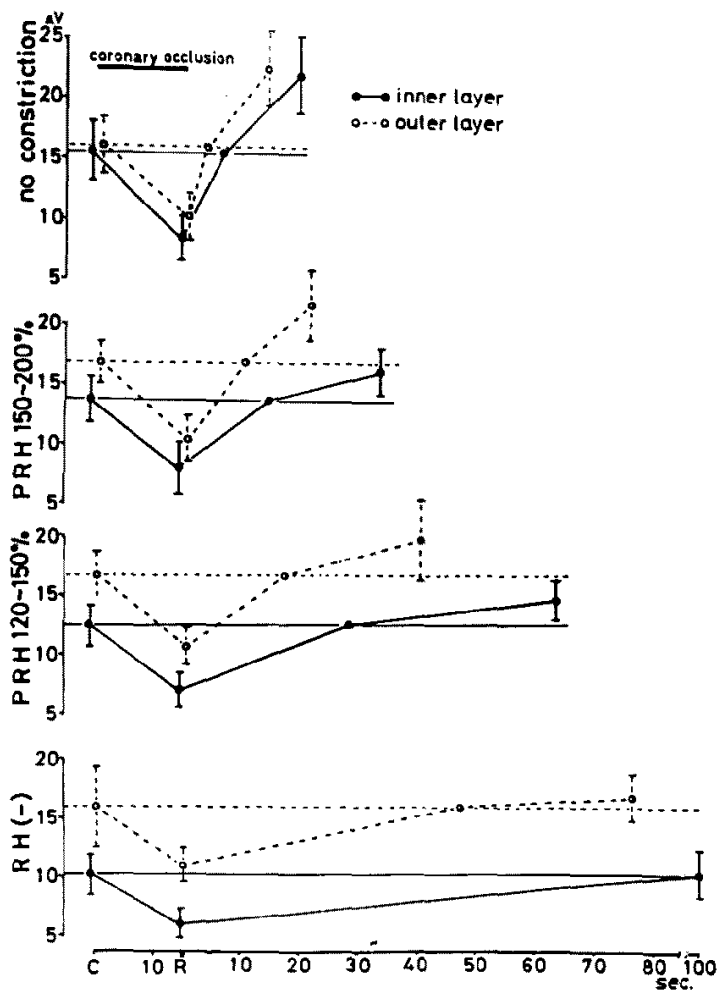

Fig. 3. Effects of coronary constriction on regional myocardial blood flow. The graphs show the blood flow before occlusion, the lowest flow during the occlusion and the peak flow following the release of the occlusion. Note that the higher the degree of the constriction, the later the blood flow returns to the resting level and arrives at peak reactive hyperemia, especially in the inner third.

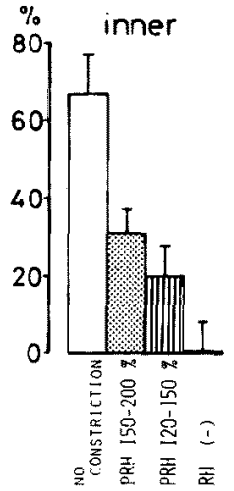

outer

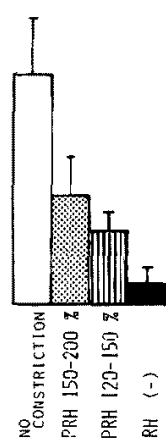

Fig. 4. Per cent changes of peak reactive hyperemia flow in regional myocardium. 
striction. The duration of reactive hyperemia, however, was prolonged in proportion to the degree of constriction. The repayment of the flow debt gradually decreased with a stepwise increase in the constriction, and the flow debt was underpaid when reactive hyperemia nearly disappeared.

\section{Discussion}

It is very important in coronary artery disease to determine the reserve of the affected myocardium to increase the blood flow in response to the vasodilatory stimuli. Gould et $\mathrm{al}^{71,8)}$ reported that reactive hyperemia began to decrease with a $40 \%$ decrease in arterial diameter. Resting mean coronary blood flow was not affected until a $85 \%$ constriction and with a $93 \%$ reduction in lumen diameter the hyperemic response disappeared.

In this paper crossed thermocouples were chosen for estimation of RMBF, using the method of Gibbs ${ }^{9)}$ as modified by Grayson, ${ }^{10)}$ Hensel, ${ }^{11)}$ and Uchida. ${ }^{12}$ ) Some doubt has been expressed about the validity of the electrodes such as heated crossthermocouple, as an estimation of RMBF, because the electrode tip in the myocardium may cause an erroneously high reading in the subepicardium if these layers move more than those in the subendocardium, and electrode insertion itself causes damage in the tissue under investigation. ${ }^{13,14)}$ With electrodes smaller than $100 \mu \mathrm{m}$ in diameter, however, tissue damage due to electrode insertion can be minimized. This, most importantly, is able to measure continuously the blood flow in subendocardium and subepicardium separately.

PRH of RMBF through the myocardium with and without coronary constriction appeared significantly later than $\mathrm{PRH}$ in the major coronary branch and moreover, in the inner third of left ventricular wall RMBF reached its peak flow rate later than in the outer third. With an increase in coronary constriction a further delay was observed in attaining PRH of RMBF, especially in the inner third. An explanation for the time lag may be made as follows: It takes time for a sufficient blood to arrive at the local myocardium because the blood must fully prime the vascular bed which collapsed during the occlusion, and the constriction of the coronary artery makes this time lag pronounced due to retarded blood flow rate. This finding suggests that a part of blood during reactive hyperemia is consumed for priming the collapsed vascular bed, and the fact mentioned above raised principal problems when PRH of RMBF was used for estimating myocardial flow reserve in regional myocardium with coronary stenosis, a necessity arose that coronary blood flow, and subendocardial and subepicardial blood flow should be measured at different time respectively. As isotope methods could not attain the 
accurate appearing time of $\mathrm{PRH}$ in the individual myocardial layers, the methods were unsuitable for studying the flow reserve in local myocardium. The heat clearance method has a great advantage in observing, with ease, $\mathrm{PRH}$ in local myocardium, though it is a semi-quantitative method and has some methodological problems as described above.

The selective decrease in blood flow to the inner third of ventricular wall during coronary constriction found in this study agrees with the result obtained by using radioactive microsphere ${ }^{15)}$ or ${ }^{86} \mathrm{Rb}$ extraction. ${ }^{16)}$ The findings suggest that a coronary artery constriction produces an abnormal distribution of intramyocardial blood flow, and that the subendocardial vessels have less dilatory reserve. With or without coronary constriction, however, the percentage increase in peak flow rate through the inner third was the same as that through the outer third during reactive hyperemia. Similar results were reported by Pitt ${ }^{17)}$ and Downey ${ }^{18}$ in hearts with normal coronary arteries. During acute myocardial ischemia the most consistent hemodynamic change observed was an elevation in the left ventricular end-diastolic pressure (LVEDP), and a marked reduction in the subendocardial tissue pressure served by the vessel was also reported. ${ }^{19,20)}$ When autoregulation of coronary flow is decreased or abolished by coronary artery stenosis, increased left ventricular preload consequently augments the underperfusion of the subendocardial region of an ischemic area. ${ }^{21}$ On the other hand, ventricular fibrillation with constant coronary perfusion pressure raised coronary blood flow ${ }^{221}$ and subendocardial blood flow. ${ }^{23}$ These reports suggest that the distribution of blood flow is dependent on gradient in myocardial tissue pressures, especially in the ischemic myocardium. A brief period (for $15 \mathrm{sec}$ ) of the total coronary occlusion did not affect or elevated LVEDP only slightly without or with relatively mild narrowing of coronary artery, while systolic myocardial tissue pressure in the subendocardial layer remained markedly low for a long time after the release of the total coronary obstruction. ${ }^{24}$ ) This decreased the extravascular support in the layer. With an advance of the coronary constriction, LVEDP rose significantly at rest and further by the total occlusion of the vessel for only $15 \mathrm{sec}$. An elevation of LVEDP caused a rise in diastolic tissue pressure produced directly by the occlusion. Hence, the extravascular support in a heart cycle during the coronary occlusion remained unchanged or rather elevated, and reactive hyperemia within the subendocardial layer decreased or abolished.

With an increase in coronary constriction it required a longer time for recovery of $\mathrm{RMBF}$ to the resting level following the release of the occlusion; flow debt calculated increased progressively. Since the duration of hyperemia in RMBF was prolonged in proportion to the increase in flow debt, overpay- 
ment, however, observed until reactive hyperemia disappeared. Lepeschkin and Surawicz ${ }^{25)}$ reported that in exercise ECG significant depression of STsegment lasted for 3 or more minutes in most cases with coronary heart disease, but less than $3 \mathrm{~min}$ in normal control subjects. It has been also stated that the electrocardiographic ST-segment depression lasts less than 2 min in normal persons ${ }^{26), 27)}$ but more than 2 to $4 \mathrm{~min}$ in persons with coronary insufficiency. ${ }^{28)}$ Furthermore, according to Lozner and Morgnroth, ${ }^{29}$ the predictive value of ST-segment depression for evaluating coronary heart disease may be enhanced if ST depression persists for 2 or more minutes before recovery after exercise. All these results suggest that the recovery time from stressinduced ischemic abnormalities in one of the important markers for detecting coronary heart disease. Moreover, in the present findings local myocardial ischemia caused by a given stress continued longer in association with a progression of coronary stenosis and such trend was greater in the subendocardial myocardium than in the subepicardial myocardium. This suggests that the time required for recovery from ischemia or ischemic abnormalities after the cessation of a certain stress might be an important marker for the severity of coronary insufficiency.

\section{REFERENCES}

1. Coffman JD, Gregg DE: Reactivc hyperemia characteristics of the myocardium. Am J Physiol 199: 1143, 1960

2. Olsson RA, Gregg DE: Myocardial reactive hyperemia in the unanesthetized dog. Am J Physiol 208: 224, 1965

3. Salisbury PF, Cross CE, Rieben PA: Acute ischemia of inner layers of ventricular wall. Am Heart J 66: 650, 1963

4. Kirk ES, Honig CR: Non-uniform distribution of blood flow and gradients of oxygen tension within the heart. Am J Physiol 207: 661, 1964

5. Grayson J, Irvine M, Parratt JR: The effects of amyl nitrite inhalation on myocardial blood flow and metabolic heat production. Brit J Pharmac Chemother 30: 488, 1967

6. Coffman JD, Gregg DE: Oxygen metabolism and oxygen debt repayment after myocardial ischemia. Am J Physiol 201: 881, 1961

7. Gould KL, Lipscomb K, Hamilton GW: Physiologic basis for assessing critical coronary stenosis. Am J Cardiol 33: 87, 1974

8. Gould KL, Lipscomb K: Effects of coronary stenosis on coronary flow reserve and resistance. Am J Cardiol 34: 48, 1974

9. Gibbs FA: A thermoelectric blood flow recorder in the form of a needle. Pro Soc Exp Biol Med 31: 141, 1933

10. Grayson $\mathrm{J}$ : Internal calorimetry in the determination of thermal conductivity and blood flow. J Physiol 118: 54, 1952

11. Hensel H, Ruef J : Fortlaufende Registrierung der Muskeldurchblutung am Menschen mit einer Calorimetersonde. Pflügers Archiv 259: 267, 1954

12. Uchida $Y$, Ueda $H$ : Effect of vagal stimulation on the regional myocardial blood flow. Saishin-Igaku 27: 784, 1972 (in Japanese)

13. Moss AJ: Intramyocardial oxygen tension. Cardiovasc Res 3: 314, 1968 
14. Jamieson D, Van DenBrenk HAS: Electrode size and tissue $\mathrm{pO}_{2}$ measurement in rats exposed to air or high pressure oxygen. J Appl Phyaiol 20: 514, 1964

15. Bache RJ, Cobb FR, Greenfield JC Jr: Myocardial blood flow distribution during ischemiainduced coronary vasodilatation in the unanesthetized dog. J Clin Invest 54: 1462, 1974

16. Mior TW, DeBra DW: Effect of left ventricular hypertension, ischemia and vasoactive drugs on the myocardial distribution of coronary flow. Circulat Res 21: 65, 1967

17. Pitt $B$ : Observations on the effect of myocardial reactive hyperemia, ischmia and nitroglycerin on regional myocardial blood flow. 2nd International Symposium on Coronary Heart Disease, Frankfurt, 1972

18. Downey HF, Bashour FA, Boatwright RB, Parker PE, Kechejian SJ: Uniformity of transmural perfusion in anesthetized dogs with maximally dilated coronary circulations. Circulat Res 37: 111, 1975

19. Meer van der JJ, Reneman RS, Schneider H, Wieberdink J: A technique for estimation of intramyocardial pressure in acute and chronic experiments. Cardiovasc Res 4: 132, 1970

20. Kreuzer $\mathrm{H}$, Schoeppe W: Der Myokarddruck bei veränderter Coronardurchblutung und bei Ischemia. Pflügers Archiv 278: 209, 1963

21. Kjekshus JK: Mechanism for flow distribution in normal and ischemic myocardium during increased ventricular preload in the dog. Circulat Res 33: 489, 1973

22. Sabiston DC, Gregg DE: Effect of cardiac contraction on coronary blood flow. Circulation 15: 14,1957

23. Cutarelli R, Levy MN: Intraventricular pressure and the distribution of coronary blood flow. Circulat Res 12: 322, 1963

24. Salisbury PF, Cross CE, Rieben PA: Intramyocardial pressure and strength of left ventricular contraction. Circulat Res 10: 608, 1962

25. Lepeschkin E, Surawicz B: Characteristics of true-positive results of electrocardiographic Master two-step exercise tests. New Engl J Med 258: 511,1958

26. Scherlis L, Sandberg AA, Wener J, Dvorkin Y, Master AM : Effects of single and double " 2 step" exercise tests upon electrocardiograms of 200 normal persons. J Mt Sinai Hosp 17: 242,1950

27. Thomas CB: Cardiovascular response of normal young adults to exercise as determined by double Master two-step. Bull Johns Hopkins Hosp 89: 181, 1951

28. Littman D, Rodman MH: Exercise test for coronary insufficiency. Circulation 3: 875, 1951

29. Lozner E, Morganroth J: New criteria to enhance the predictability of coronary artery disease by exercise testing in asymptomatic subjects. Circulation 56: 799. 1977 